\title{
EFFECTS OF ACETALDEHYDE ON THE MEMBRANE POTENTIAL AND MEMBRANE RESISTANCE OF THE IDENTIFIED NEURONS IN THE ABDOMINAL GANGLION OF APLYSIA KURODAI
}

\author{
Ryuji TAKEDA and Yasunori MOMOSE \\ Department of Pharmacology, Faculty of Medicine, \\ Toyama Medical and Pharmaceutical University, Sugitani, Toyama 930-01, Japan
}

Accepted October 29, 1979

\begin{abstract}
Actions of acetaldehyde on membrane potentials and membrane resistances of Aplysia neurons were studied using an intracellular recording and current injection technique. Several functionally different neurons in the abdominal ganglion of $A$. kurodai were identified on the basis of their morphological and electrophysiological characteristics. Application of between 5 and $50 \mathrm{mM}$ acetaldehyde produced depolarization of the membrane, in all types of cells investigated. This depolarization was accompanied by an increase in the rate of spike discharge. The amplitude and the rates of rise and fall of the action potential were reduced and the duration of the spike was prolonged. Acetaldehyde had no significant effect on the input resistances of ganglion cells. These actions of the aldehyde were observed to be similar in the completely isolated neuron-soma preparation separated from the neighbouring cells or synapses.
\end{abstract}

Acetaldehyde induces an anesthetic-like state in animals and studies in the field of behaviour and EEG have revealed that the drug also produces variable excitatory effects on the central nervous system (1-4). Despite these apparent effects on the nervous system, there is little documentation on the electrophysiological data related to the direct cellular effects of acetaldehyde.

Our study was an attempt to examine the effects of acetaldehyde on the membrane electrical activities of molluscan central neurons. The nervous system of Aplysia provides many advantages for cellular studies of drug actions since many of the cells are large, can be easily penetrated by microelectrodes and can be identified on the basis of their morphological and functional properties (5). Accordingly, it is possible to study an identifiable neuron in a number of different preparations. Throughout the experiments we used the abdominal ganglion of $A$. kurodai, the most common species in Japan $(6,7)$.

\section{MATERIALS AND METHODS}

A. kurodai, weighing between 100 and $300 \mathrm{~g}$, were collected in the Japan Sea in the vicinity of Toyama Bay. This species occurs in abundance from spring to summer but is extremely rare from August to December. The present experiments were carried out over a three year period in the months of April, May, June and July.

The abdominal ganglion was dissected and mounted on a recording chamber which 
was continuously circulated with artificial sea water (ASW) at a constant rate of $2 \mathrm{ml} / \mathrm{min}$. The composition of the ASW was as follows (in $\mathrm{mM}$ ): $\mathrm{NaCl} 494, \mathrm{KCl} 11, \mathrm{CaCl}_{2} 11, \mathrm{MgCl}_{2}$ $19, \mathrm{MgSO}_{4} 30$, and Tris base 10. The temperature of the solution was kept constant at $15-16^{\circ} \mathrm{C}$ and the $\mathrm{pH}$ was adjusted at 7.8 .

Two independent glass microelectrodes filled with $3 \mathrm{M}-\mathrm{KCl}$ or $0.6 \mathrm{M}-\mathrm{K}_{2} \mathrm{SO}_{4}$ with resistances of 5-20 M $\Omega$ were introduced into a single cell, under visual control, one electrode for recording membrane potentials and the other for passing current. Membrane potentials and injected currents were displayed and photographed on an oscilloscope using conventional methods. Differentiated action potentials were recorded through a differential operational amplifier (time constant, 0.2-0.5 msec) (RPD-5, Nihon Kohden Co., Tokyo). Stimulation of the appropriate neural input to the ganglion was accomplished by means of bipolar platinum electrodes.

In one series of experiments, completely isolated neurons were used in order to eliminate the influence of synaptic bombardments on the activity in a given cell. For this purpose, the isolated single neuron-soma, which was completely separated from the neighbouring cells and synapses, was obtained following the procedures described by Chen et al. (8). Drugs were applied when the resting membrane potentials and impulse activities had recovered fully to the normal level, after isolation procedures.

Acetaldehyde was freshly distilled from the stock solution and then dissolved into the ASW just before use. Drugs were directly applied to the tissue by perfusion.

\section{RESULTS}

Identification of neurons in the abdominal ganglion: Four different types of cells were identified according to the criteria described by Frazier et al. (5). 1) The well-known giant cell was easily recognized as the largest one was and deeply pigmented on the dorsal surface of the right rostral quarter ganglion (RRQG). It was silent in the standard experimental condition (Fig. 1A) and hyperpolarized by acetylcholine; therefore, it was an $\mathrm{H}$-cell. Thus, this neuron may be homologous to cell $\mathrm{R}_{2}$ in A. californica (5). 2) A typical bursting cell was identified in the right caudal quarter ganglion (RCQG). It seemed to be homologous to $\mathrm{R}_{15}$, since its appearance (white or opaque pigmentation), localization (commonly in the center of the RCQG), and physiological properties (bursting firing pattern, spontaneous and evoked EPSPs, depolarizing response to acetylcholine) were all quite similar to those of $R_{15}$ (5) (Fig. 1C). 3) Two or three bursting cells were usually found on the left rostral quarter ganglion (LRQG). 4) Likewise, a group of white cells in the RRQG, which fired spontaneously at a fairly constant rate, was identified as the regularly beating cells (Fig. 1B). These two groups of cells, 3) and 4), were all $\mathrm{H}$-cells, and their electrophysiological properties resembled those of $\mathrm{L}_{2-4,6}$ and $\mathrm{R}_{3-8}$ in A. californica (5).

Other large numbers of cells could not be easily identified as their position and spontaneous activities varied with the preparation. In the following experiments, these unidentified cells, which were classified only on the basis of their spontaneous activities and responses to acetylcholine, were also included for the analysis of the drug action (Table 1). 
12

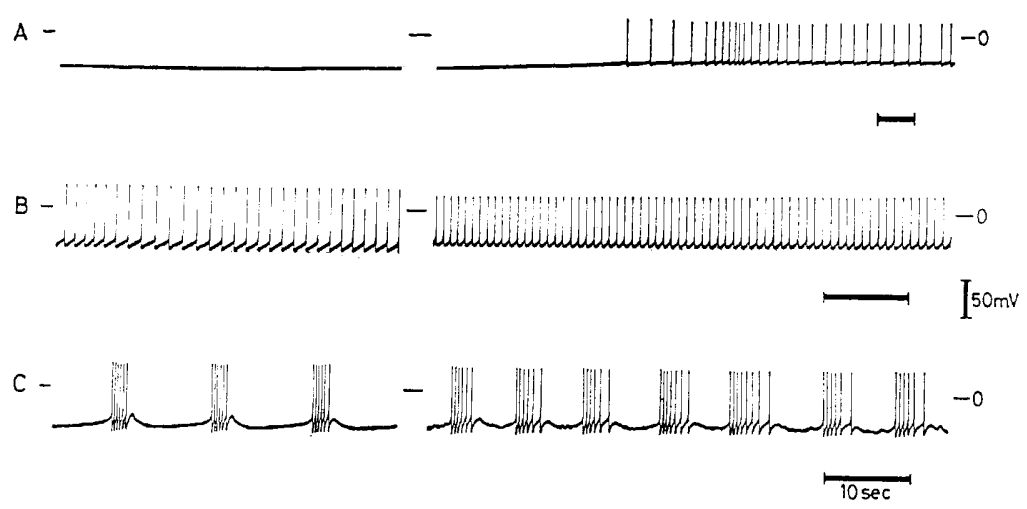

Fig. 1. Effects of acetaldehyde on the intracellular membrane potentials of different neurons identified in the abdominal ganglion of $A$. kurodai. A-C were recorded from a silent giant cell in the RRQG (A), a regularly beating cell in the RRQG (B), and a typical bursting cell in the RCQG (C), respectively. (1): Before, and (2): during the action of $20 \mathrm{mM}$ acetaldehyde. Zero potential is indicated by a short horizontal bar.

TABLE 1. The resting membrane potentials of different types of cells in the abdominal ganglion of Aplysia kurodai in the absence and presence of acetaldehyde

\begin{tabular}{|c|c|c|c|c|c|}
\hline \multicolumn{3}{|c|}{ Cell type } & \multicolumn{3}{|c|}{$\mathrm{RMP}(\mathrm{mV})$} \\
\hline firing pattern & $\mathrm{ACh} r$ & esponse & before & $\begin{array}{l}\text { acetaldehyde } \\
(30 \mathrm{mM})\end{array}$ & $\begin{array}{c}\text { difference } \\
\text { (depolarization) }\end{array}$ \\
\hline \multicolumn{6}{|l|}{ Silent cell } \\
\hline Identified in RRQG & $\mathrm{H}$ & $(15)$ & $-59.9+1.9$ & $-52.0 \pm 1.9$ & $7.6 \pm 0.9$ \\
\hline Unidentified & $\mathrm{D}$ & $(8)$ & $-52.0+3.7$ & -44.84 .0 & $7.3 \pm 1.7$ \\
\hline \multicolumn{6}{|l|}{ Regularly beating cell } \\
\hline Identified in RRQG & $\mathrm{H}$ & (14) & $-47.8 \longleftarrow 2.4$ & $-42.9 \div 2.4$ & $4.9-0.8$ \\
\hline Unidentified & $\mathrm{H}$ & $(7)$ & $-43.6+3.5$ & $-39.1 \pm 3.6$ & $4.4 \pm 0.8$ \\
\hline Unidentified & $\mathrm{D}$ & (10) & $-41.7 \pm 2.1$ & $-38.4+1.9$ & $3.3 \div 0.5$ \\
\hline \multicolumn{6}{|l|}{ Bursting cell } \\
\hline Identified in LRQG & $\mathrm{H}$ & $(10)$ & $-43.2+2.6$ & $-35.9 \pm 3.0$ & $7.3 \pm 0.8$ \\
\hline Identified in RCQG & $\mathrm{D}$ & (23) & $-48.3 \pm 1.2$ & $-42.0 \pm 1.4$ & $6.4 \pm 1.1$ \\
\hline
\end{tabular}

Values are the mean - S.E. The number of cells tested for each group is in parentheses.

Effects of acetaldehyde on the resting membrane potentials: Application of acetaldehyde at the concentration of between 5 and $50 \mathrm{mM}$ produced depolarization of the membrane in all types of cells, in a dose-dependent and reversible manner. The threshold concentration of the drug for detecting the membrane potential changes was between 1 and $5 \mathrm{mM}$.

In Fig. 1, typical examples of responses to acetaldehyde in three identified cells with different firing patterns are shown. The silent cell was gradually depolarized and induced repetitive action potentials by $20 \mathrm{mM}$ of acetaldehyde (Fig. 1A). At a lower concentration $(5-10 \mathrm{mM})$ the drug produced only a slight depolarization without spike generation. The 
regularly beating cell (Fig. 1B) and the typical bursting cell (Fig. 1C) were similarly depolarized by the aldehyde. In some cases in the bursting and beating cells, a slight hyperpolarization of the membrane was accompanied by a disappearance of the spike activity observed during washout of the drug.

The magnitude of the depolarization varied from cell to cell. Table 1 summarizes the results of these experiments on different cell groups. Acetaldehyde was administered for $10-30 \mathrm{~min}$ in the concentration of $30 \mathrm{mM}$. Within the initial $5 \mathrm{~min}$ of perfusion with acetaldehyde the membrane potential changes reached a peak and this level was maintained thereafter. The changes of the membrane electrical activities were usually determined $10 \mathrm{~min}$ after introduction of the drug. Since no steady-state potentials were obtained in the spontaneously active neurons, the highest value of the recorded potentials during the silent period was registered as the resting membrane potential (RMP). It would seem that the magnitude of depolarization produced by acetaldehyde was larger in the silent cell groups than in the regularly beating cells. In bursting cells, the drug also caused a relatively large depolarization. This was due to a decrease in the interburst hyperpolarization (Fig. 1C). The action of acetaldehyde was much the same in both D- and H-cells (Table 1).

Effects on the action potentials: The membrane depolarization was always accompanied by a marked increase in the rate of spike discharge (Fig. 1). The mean spike frequency in 31 regularly beating neurons during a control period was 72 spikes/min (ranging from 10 to $122 / \mathrm{min}$ ), and it increased approximately double during the drug administration, with the mean value of $120 / \mathrm{min}$ (ranging from 18 to $340 / \mathrm{min}$ ). In bursting pacemaker cells, the number of spikes in a burst and the duration of burst were increased, and the interburst intervals usually decreased (Fig. 1C). With a larger dose of acetaldehyde, the bursting pattern was converted to a continuous type of discharge.

The amplitude of action potentials was reduced with all applications of acetaldehyde. This was mainly due to a decrease in the overshoot of the spike. The after-hyperpolarization was also decreased (Figs. 1,2). The mean values of the spike size in the regularly beating neurons before and after the drug administration were $79.9 \pm 2.6 \mathrm{mV}$ and $70.2 \pm 3.5 \mathrm{mV}$ $(\mathrm{n}=31)$. At the same time, the maximum rates of rise and fall of the action potentials were decreased from $41.8 \pm 3.5 \mathrm{~V} / \mathrm{sec}$ to $31.7 \pm 2.8 \mathrm{~V} / \mathrm{sec}$ and from $39.2 \pm 4.0 \mathrm{~V} / \mathrm{sec}$ to $28.3 \pm 3.2 \mathrm{~V} /$
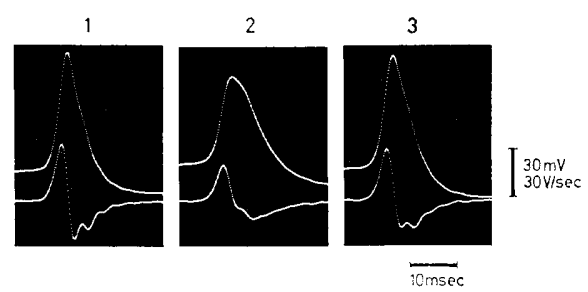

Fig. 2. Effect of acetaldehyde on the action potential. Upper trace: spontaneous action potentials recorded from a regularly beating cell. Lower trace: electrically differentiated action potentials (time constant, $0.2 \mathrm{msec}$ ). Records (1) and (2) were taken before and during application of $30 \mathrm{mM}$ acetaldehyde.

Record (3) was taken 15 min after washout of the drug. 
sec, respectively. The duration of the spike measured at $50 \%$ of its amplitude (half-duration) was $10.2 \pm 0.8 \mathrm{msec}$, and increased to $14.2 \pm 1.1 \mathrm{msec}$ during the stage of depolarization induced by acetaldehyde (Fig. 2).

Effects on the input resistance: The input resistance of the membrane was measured

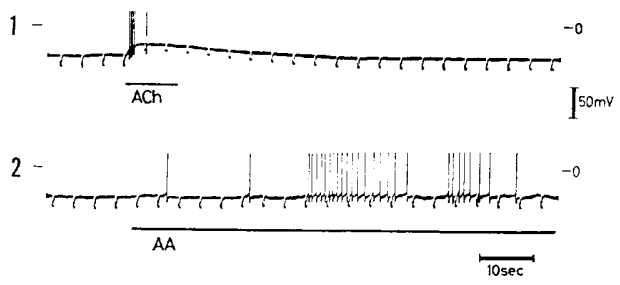

Fig. 3. Effects of acetaldehyde (AA) and acetylcholine (ACh) on the membrane potential and membrane resistance of an unidentified silent D-cell. (1) Acetylcholine $\left(10^{-6} \mathrm{~g} / \mathrm{ml}\right)$, and (2) acetaldehyde $(20 \mathrm{mM})$ were applied during the bar. Hyperpolarizing currents with a constant intensity $(2 \mathrm{nA}, 450 \mathrm{msec})$ were applied every $5 \mathrm{sec}$. Note a marked decrease in the input resistance during depolarization induced by acetylcholine, but no change by acetaldehyde.

A

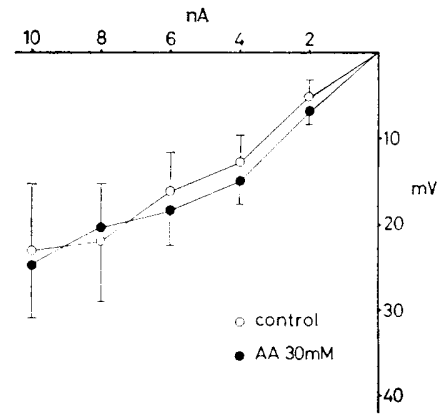

B

1

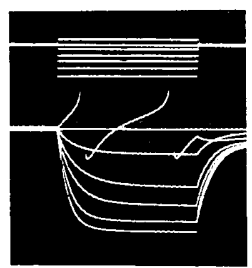

2

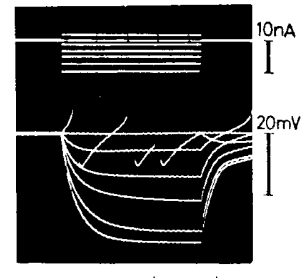

$\overline{200 \mathrm{msec}}$

FIG. 4. Effect of acetaldehyde on the membrane resistance. A: Current-voltage relationships obtained from an identified giant cell. The ordinate is membrane potential (hyperpolarization downward) and the abscissa is current (inward current to the left). Open circles obtained from control; solid circles, during the action of $30 \mathrm{mM}$ acetaldehyde (AA). Each point represents the mean value obtained from five cells; short vertical bars show standard errors. B: A specimen of superimposed traces of electrotonic potentials (lower lines) and current pulses (upper lines) obtained in one of the experiments shown in A. B-1 is control; B-2, during the application of $30 \mathrm{mM}$ acetaldehyde. Depolarization caused a repetitive firing. 


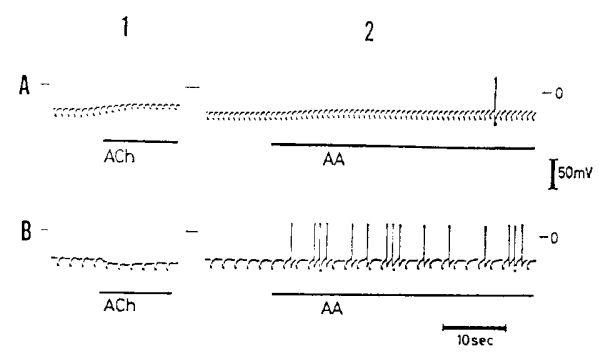

FIG. 5. Effects of acetaldehyde on the completely isolated neurons. The cell (A) and (B) showed depolarization and hyperpolarization in response to acetylcholine (ACh) $\left(10^{-6} \mathrm{~g} / \mathrm{ml}\right)$, respectively. Acetaldehyde $(\mathrm{AA})(20 \mathrm{mM})$ depolarized both cells but did not change the input resistances. Hyperpolarizing square pulses with a constant intensity $(3 \mathrm{nA}, 200 \mathrm{msec})$ were applied at a given interval during these experiments.

by the application of hyperpolarizing current with a constant intensity $(1-10 \mathrm{nA}$, with a pulse duration of 200-500 msec). In Fig. 3 the course of change in the membrane potential and membrane resistance was demonstrated during application of acetaldehyde and acetylcholine. Acetylcholine produced depolarization, which was accompanied by a decrease in the membrane resistance in this cell (Fig. 3-1). On the other hand, acetaldehyde induced no significant change in the membrane resistance yet the membrane was depolarized (Fig. 3-2).

Figure 4 shows the relationships between the size of electrotonic potentials and the strength of currents in the absence and presence of acetaldehyde. It may be seen that acetaldehyde did not induce any significant change in the input resistance in this identified silent cell. In the same way, the current-voltage relationships were determined in the other 15 silent and 15 spontaneously active neurons, using constant current square pulses. Although in some spontaneously active cells a slight increase in the input resistance was observed by acetaldehyde, calculations of the I/V relationships obtained from these 30 neurons revealed that there was no statistically significant effect of acetaldehyde on the membrane resistances in the region of the -40 to $-70 \mathrm{mV}$ membrane potential range.

Effects on the completely isolated neurons: In view of the possibility that these changes in the membrane potentials and resistances could be due to some effects of the drug on the synaptic transmission, acetaldehyde was directly applied to the isolated single neuronsoma $(8,9)$.

Acetaldehyde produced depolarization of the membrane in the completely isolated neurons in a manner similar to that seen in the case of intact ganglion cells (Fig. 5). This was shown in both D- (Fig. 5A) and H-cells (Fig. 5B). Figure 5 also indicates that this depolarization was not accompanied by a change in the membrane resistance. Acetylcholine, on the other hand, decreased the input resistance in both cases (Fig. 5-1).

\section{DISCUSSION}

According to Baba (6), the general structures including viscera of A. kurodai resemble 
the Atlantic and Mediterranean species, A. punctata. Although no histological study of the fine structures of the abdominal ganglion has been undertaken, it does appear that some of the identifiable neurons in $A$. kurodai are quite similar to those of other species, on the basis of the electrophysiological properties $(5,9)$.

Application of acetaldehyde produced depolarization of the membranes in all kinds of cells we investigated. Such was also the case with completely isolated neurons. It is obvious, therefore, that the membrane depolarization induced by the aldehyde could not be secondary to the effects of the drug on the neighbouring cells nor on the synaptic transmission. Furthermore, this action of acetaldehyde was neither dependent on the pacemaker activities nor on the cholinergic chemical natures of the cell membranes. These results indicate that the drug exerts its effect on relatively unspecific mechanisms which are probably involved in controlling the membrane excitabilities.

At present it is impossible to interpret the ionic basis of the depolarization induced by acetaldehyde in relation to its action on the membrane resistance. Since the depolarization took place without any significant change in the input resistance, it may be assumed that acetaldehyde affects such mechanisms that are not coupled with the passive membrane permeabilities of ions. The present experiments, however, could not conclusively rule out the possibility that the drug may alter the membrane permeability to some ions which contribute only a small portion of the total resting conductance. Since the depolarization induced by acetaldehyde markedly decreased in $\mathrm{Na}^{+}$-free solutions (unpublished observation), it is possible that this action of the drug is, at least in part, due to an increase in $\mathrm{Na}^{+}$permeability.

Acetaldehyde reduced spike amplitude, especially the overshoot. The spikes in Aplysia neurons are dependent not only upon $\mathrm{Na}$ but also upon $\mathrm{Ca}$ ions (10). It is interesting to note that this aldehyde also reduces the action potential in the smooth muscle membrane of the guinea-pig taenia caecum, in which the action currents are principally carried by $\mathrm{Ca}$ ions (11).

Increase of the spike discharge induced by acetaldehyde produces a stimulatory action on this nervous system. It is known that general anesthetics transiently produce varying degrees of CNS excitation. The excitatory actions of acetaldehyde have also been observed in mammalian CNS, although the effective dose of the drug is widely different between the vertebrate and invertebrate preparations. Intravenous administration of acetaldehyde caused a marked but transient activation of EEG in cats (4). Hyperpnea and other behavioural excitement, such as abnormal gait or jumping, are produced by this aldehyde in dogs, cats, and rats (1-4). This respiratory excitement and/or behavioural disturbance may sometimes mask the anesthesia (12). The actions of acetaldehyde in the abdominal ganglion of Aplysia may be accompanied by a complex combination of disorganization, disinhibition, and stimulation of excitatory as well as inhibitory neurons. To clarify the action of acetaldehyde on the integrative function of the CNS, we are now doing further experimental studies of action of the drug on synaptic transmissions among these neurons. 


\section{REFERENCES}

1) Supniewski, J.V.: The toxic action of acetaldehyde on the organs of vertebrates. J. Pharmacol. exp. Ther. 30, 429-437 (1927)

2) Handovsky, H.: Au sujet des propriétés biologiques et pharmacodynamiques de l'acétaldéhyde. C. r. Séanc. Soc. Biol. 117, 238-241 (1934)

3) Koppanyi, T.: Acetaldehyde, a volatile anesthetic and sympathetic stimulant. Anesthesiology 6, 603-611 (1945)

4) Ogata, H.: Central action of acetaldehyde: Effects of acetaldehyde on the electroencephalogram of the cat. Med. J. Shinshu Univ. 9, 171-182 (1964)

5) Frazier, W.T., Kandel, E.R., Kupfermann, I., Waziri, R. and Coggeshall, R.E.: Morphological and functional properties of identified neurons in the abdominal ganglion of Aplysia californica. J. Neurophysiol. 30, 1288-1351 (1967)

6) Baba, K.: Opisthobranchia in Japan (I). J. Dept. Agric. Kyushu Imp. Univ. 5, 195-237 (1937)

7) Usuki, I.: Studies on the life history of Aplysiae and their allies in the Sado district of the Japan Sea. Sci. Rep. Niigata Univ., Ser. D (Biology) 7, 91-105 (1970)

8) Chen, C.F., von Baumgarten, R. And Takeda, R.: Pacemaker properties of completely isolated neurones in Aplysia californica. Nature, New Biol. 233, 27-29 (1971)

9) TakedA, R.: Activities of the pacemaker neurones in the abdominal ganglion of Aplysia. Shinshu med. J. 22, 215-223 (1974) (in Japanese)

10) Geduldig, D. And Gruener, R.: Voltage clamp of the Aplysia giant neurone: early sodium and calcium currents. J. Physiol. 211, 217-244 (1970)

11) Takeda, R. And Momose, Y.: Effects of acetaldehyde on electrical and mechanical activities of guinea-pig taenia coli. Archs int. Pharmacodyn. Thér. 232, 14-27 (1978)

12) Akabane, J.: Aldehydes and related compounds. International Encyclopedia of Pharmacology and Therapeutics, Sec. 20, Alcohol, p. 523-560, Pergamon Press, Oxford (1970) 